\title{
Schistosomal myeloradiculopathy in a low-prevalence area: 27 cases (14 autochthonous) in Campinas, São Paulo, Brazil
}

\author{
André Ricardo Ribas Freitas ${ }^{+}$, Augusto César Penalva Oliveira, Luiz Jacintho Silva \\ Departamento de Clínica Médica, Faculdade de Ciências Médicas, Universidade Estadual de Campinas, Campinas, SP, Brasil
}

\begin{abstract}
Schistosomal myeloradiculopathy (SMR) is a form of schistosomiasis that is not linked with a high worm burden but rather is found in patients who have been sporadically exposed to Schistosoma mansoni. This paper aims to determine the occurrence of SMR in a low-endemic area with urban transmission in Campinas, São Paulo, Brazil. A retrospective study was performed, identifying confirmed cases in the two largest public hospitals on the region. Patients were diagnosed with SMR using standardised criteria, common clinical parameters, evidence of schistosomal infection and exclusion of other causes of myelopathy. A total of 27 patients were identified; 19 (85.2\%) were men and four $(14.8 \%)$ were women, ranging from 13-57 years of age (mean $=31.2 ;$ standard deviation $=12.8)$. Patients were classified as autochthonous $(n=14 ; 51.9 \%)$ or allochthonous $(n=11 ; 40.7 \%)$ and epidemiological data could not be obtained for two patients (7.4\%). The clinical parameters of these patients were not different from previous studies. The sensitivity of serum immune reactions, cerebrospinal fluid immune reactions and parasitological stool examinations in identifying infected individuals was $87.5 \%$, 93.8\% and 40\%, respectively. The epidemiological importance of these findings and their relationship with the control policies of schistosomiasis are discussed.
\end{abstract}

Key words: neuroschistosomiasis - spinal cord diseases - schistosomiasis - morbidity - epidemiologic surveillance - epidemiology

Schistosomiasis control programs have had significant success controlling the morbidity caused by these infections. However, these programs have not decreased the transmission area in Brazil and in other regions around the world (WHO 2001). Schistosomiasis is prevalent in 76 countries and affects 200 million individuals, of whom 100 million present some type of clinical occurrence and 20 million present a more severe form of the disease (WHO 2002). The disease occurs predominantly in the poorest regions of a country and is associated with poor sanitary conditions and adverse social economical conditions. It is estimated that 2.5 million people were infected in Brazil in 2000 and 25 million people are at risk of infection in a 1 million $\mathrm{km}^{2}$ area (WHO 2001).

Schistosomal myeloradiculopathy (SMR) is the most severe ectopic form of schistosomiasis (Lambertucci 1993). Three main species of Schistosoma cause lesions in the central nervous system: Schistosoma mansoni, Schistosoma haematobium and Schistosoma japonicum. However, while $S$. japonicum is frequently associated with clinical cerebral lesions, cases of SMR caused by $S$. japonicum have only been rarely described.

The pathogenesis of SMR has not been fully elucidated, but is accepted that the inflammatory response of the host causes destruction of nervous tissues around the egg that is deposited on the spinal cord and that this inflammation also plays a central role in the medullar lesion. SMR has been reported more frequently in patients with a chronic intestinal form of schistosomiasis and

+ Corresponding author: arrfreitas@yahoo.com.br

Received 9 January 2009

Accepted 16 September 2009 appears to be less frequent in acute and hepatosplenic forms of the disease (Pittella 1991, 1997, Gonçalves et al. 1995, Ferrari et al. 2001, Silva et al. 2004a, Lambertucci et al. 2005). Clinically, SMR presents with lower back pain radiating to the lower limbs, followed by a decrease in the muscular strength in these limbs and the loss of sphincter control. Generally, the progression of the disease may take days or weeks. SMR is diagnosed based on the clinical manifestations, the clinical determination of schistosomal infection using immunological or parasitological methods and the exclusion of other causes of myelopathy (CDC 1984, MS/SVS 2006). The prognosis depends on how soon proper therapy (anti-schistosomal drugs and corticosteroids) can be started.

The prevalence of SMR is unknown and the number of reported cases has increased in the past few years, probably due to the improvement of diagnostic methods. Brazil has had the greater number of reported SMR cases. A series of cases from high-endemic areas have been published (Nobre et al. 2001, Peregrino et al. 2002, Ferrari et al. 2004) and there have been reports of isolated cases in patients that have been in transmission areas (CDC 1984, Gellido et al. 2000, Chen et al. 2006). As SMR is a form of schistosomiasis that is not related to a high worm burden, it is likely to occur in low-endemic areas. The objective of this paper was to determine the occurrence of SMR in a low-endemic area around Campinas, São Paulo (SP), Brazil.

\section{PATIENTS, MATERIALS AND METHODS}

Studied area - Campinas is a city of nearly one million inhabitants (SMS 2007), located in SP (22 50'S $\left.47^{\circ} 00^{\prime} \mathrm{W}\right)$, the seat of Campinas metropolitan region, which is composed of 19 cities and towns with approximately 2,620,000 inhabitants distributed over $3,645,666 \mathrm{~km}^{2}$. Campinas is economically character- 
ised as an industrial, agroindustrial and service industry with many scientific research institutions. It also has a large number of health facilities (SEP/SP 2007). Epidemiologically, SP is characterised as having isolated areas of schistosomiasis (Silva 1992, CamargoNeves 2007). Although schistosomiasis is a disease requiring mandatory notification, it is rarely done. The number of cases of schistosomiasis reported by the city of Campinas averaged 455 per year between the years 2000-2005 and, of these cases, 109 (23.9\%) were considered autochthonous (SES/CVE-SP 2008).

Study design - A retrospective study was performed in the Hospital de Clínicas of Universidade Estadual de Campinas (HC-UNICAMP) and in the Hospital e Maternidade Celso Pierro of Pontifícia Universidade Católica de Campinas (HMCP-PUC Campinas). These hospitals were selected because together they support $71 \%$ of the patients from Sistema Único de Saúde of Campinas. In addition, these hospitals have a variable proportion of patients from other cities in the metropolitan regions and from other Brazilian regions, in addition to having outpatient clinics, infirmaries and diagnostic centres that are able to treat patients with SMR (SMS 2007). The patients were selected through an active search of the admission data bases, outpatient records, results of lab tests and the National System of Information of Diseases with Mandatory Notification (SINAN). Patients diagnosed with SMR that were examined in these hospitals between 1995-2005 were included in this study. Patients that did not meet the established diagnostic criteria were excluded. The criteria were the following: (i) spinal or myeloradicular syndrome, (ii) demonstration of schistosomal infection by parasitological or immunological methods and (iii) exclusion of other causes of myeloradiculopathy (CDC 1984, MS/SVS 2006). Clinical, epidemiological and laboratory data, as well as imaging examinations of the patients, were gathered. The patients were classified as "autochthonous" (i.e., those who were in contact with contaminated bodies of water around Campinas region and not in other regions), "allochthonous" (i.e., those who were in contact with contaminated bodies of water in other endemic regions and had no contact with contaminated bodies of water around the region of Campinas), "undetermined" (i.e., those whose previous exposure standard does not fit in any previously mentioned) or patients "without epidemiological data" (i.e., those whose information did not allow classification and could not be located for an interview). All autochthonous patients were interviewed for possible data correction about the exposure.

The patients were classified according to the outcome: "complete recovery", the absence of symptoms and normal neurological examination, "partial recovery with no functional limitations", marked improvement but also presented mild symptoms that did not hinder daily activities (e.g., patients with paraesthaesia in the lower limbs or slight difficult in urinating), "partial recovery with functional limitations", symptoms that change the daily routine of the patient (e.g., the use of a bladder probe or a patient who walks with some kind of support) or "absence of recovery", the absence of a marked recovery or only a slight recovery that has not changed the patient's functional condition (Peregrino et al. 2002, Ferrari et al. 2004).

\section{TABLE I}

Frequency of symptoms and time passed between the start of clinical problems and presentation of each symptom of 27 patients with presumptive diagnosis of schistosomal myeloradiculopathy examined in hospitals of Campinas, São Paulo, Brazil between 1995-2005

\begin{tabular}{|c|c|c|c|c|c|c|c|c|}
\hline \multirow[t]{2}{*}{ Clinical information } & \multicolumn{3}{|c|}{ Frequency } & \multicolumn{5}{|c|}{$\begin{array}{l}\text { Time in days from the start of the clinical status until } \\
\text { the symptom manifestation }\end{array}$} \\
\hline & $\mathrm{N}$ & $\mathrm{n}^{a}$ & $\%$ & Mean & Median & SD & Minimum & Maximum \\
\hline Lower limbs paresis & 27 & 27 & 100 & 35.5 & 5 & 94.7 & 0 & 360 \\
\hline Sensitivity alteration in lower limbs & 27 & 27 & 100 & 83.2 & 1 & 215.1 & 0 & 730 \\
\hline Bladder dysfunction & 25 & 27 & 92.6 & 35.8 & 7 & 84.6 & 0 & 355 \\
\hline $\operatorname{Triad}^{b}$ & 25 & 27 & 92.6 & 69.8 & 7 & 168.8 & 0 & 730 \\
\hline Anal dysfunction & 19 & 25 & 76 & 67.1 & 7 & 125.1 & 0 & 365 \\
\hline Erectile dysfunction $^{c}$ & 9 & 12 & 75 & 149.8 & 48 & 278.3 & 3 & 730 \\
\hline Back pain & 20 & 27 & 74.1 & 5.7 & 0 & 20.7 & 0 & 90 \\
\hline Pain in lower limbs & 18 & 27 & 66.7 & 20.9 & 0 & 81 & 0 & 335 \\
\hline Other sensitivity changes in lower limbs & 25 & 27 & 92.6 & 52.6 & 4 & 160.7 & 0 & 730 \\
\hline Walking disability & 16 & 27 & 59.3 & 32.9 & 5 & 88.4 & 0 & 350 \\
\hline
\end{tabular}

$a$ : because this is a retrospective study, not all patients provided all information. Only patients whose information was available have been included in the calculation (n); $b$ : triad: paresis, some sensitivity alteration in lower limbs (e.g., pain, paraesthesia, dysesthesia) and bladder dysfunction; $c$ : to calculate the relative frequency of erectile dysfunction, only men whose clinical records presented this information were included; SD: standard deviation. 
Result analysis - The statistical program MINITAB Release 14.12.0 Statistical Software was used for data analysis. To describe the findings, the central tendency and variability measures were used in addition to graphic and tabular resources of descriptive statistics. For proportion evaluation, the proportion equality test and Fisher's exact test were used. The evaluation of the differences between continuous variable distributions was done using Mann-Whitney's test. To define the geographic coordinates of residence and infection locations and to calculate these distances for inhabitants of Campinas region, the program Google Earth 4.0.2416 (beta) Build Date Oct 312006 for Microsoft Windows XP was used. To calculate the distance between the residence of patients living in Campinas and the lakes where these patients were infected, the program Map Info 8.0 was used.

Ethical aspects - This research was authorised by the Ethical Committee of the Faculdade de Ciências Médicas-UNICAMP, respecting the law 196/96 of the Ministry of Health and National Health Council (MS/ CNS 1996). Regarding the guidelines of Declaration of Helsinki, modified in Hong Kong in 1989 to preserve the ethical aspects of research, all patients provided informed consent after being provided an explanation of the Informed Consent Form, which was previously approved by the Institutional Ethical Committee.

\section{RESULTS}

Epidemiological profile of patients - A total of 30 patients who were diagnosed with SMR were identified. Of these, three were excluded from the study: two because other diseases had not been investigated properly and one who tested positive for human T lymphotropic virus (HTLV). Therefore, 27 patients remained in the study, 22 from HC-UNICAMP and five from HMCP-PUC Campinas. Of these 27 patients, 11 (41\%) were notified by SINAN. The remaining patients were located exclusively through the hospital registry database and the active search of lab tests. From these 27 patients, seven (patients 2, 16, 17, 18, 11, 14 and 25) had already been published in national journals by other authors as isolated cases (Tedrus et al. 1996, 1999, Lima et al. 1999, Faria et al. 2002).

Twenty-three (85.2\%) patients were male and four $(14.8 \%)$ were female. The age at the time of the diagnosis ranged from 13-57 years [mean $=31.2$; standard deviation $(\mathrm{SD})=12.8$ and median $=29]$ and the time between the first visit and the diagnosis averaged 70.6 days $($ median $=19 ; \mathrm{SD}=166.9)$.

Based on the probable location of infection, the patients were classified as autochthonous $(\mathrm{n}=14$; $51.9 \%$ ), with 11 patients from Campinas city and three from other towns in this region, allochthonous $(\mathrm{n}=$ $11 ; 40.7 \%$ ) or patients without epidemiological data $(\mathrm{n}=2 ; 7.4 \%)$. No patient was classified as "undetermined". All patients classified as autochthonous were infected in foci located in urban areas no more than $4.450 \mathrm{~m}$ from their homes. Except for patient 9, who was infected during his work activities, the remaining autochthonous patients were infected during sporadic recreational activities. All allochthonous patients were infected in high-endemic areas in the states of Minas Gerais (MG), Alagoas, Sergipe or Bahia in Brazil.

Clinical presentation - The most frequent symptom was lower limbs paresis $(\mathrm{n}=27 ; 100 \%)$, followed by sensitivity changes in the lower limbs and bladder dysfunction $(\mathrm{n}=25 ; 92.6 \%)$. All three symptoms (bladder dysfunction, paresis and sensitivity changes in the lower limbs) were observed in $25(92.6 \%)$ patients. Half of the patients that presented these symptoms reported the symptoms seven days after the beginning of the manifestation. Although thoracic and back pain is often reported as an early symptom, it was not among the most frequently reported symptoms (Table I), affecting only 18 patients $(66.7 \%)$. In contrast, erectile dysfunction, although a late symptom (median of start 48 days), had a higher relative frequency among men $75 \%$ (12 patients). As expected, there was no statistical difference in the relative frequency of the symptoms presented by the autochthonous and allochthonous patients (Table II).

Results of complementary examinations - Magnetic resonance imaging (MRI) or computerised tomography were performed in all cases and helped to exclude other causes of myelopathies. Figs 1 and 2 show the MRI of patient 2, with gadolinium contrast and granular aspect.

Among non-specified lab results from the initial exam, hyperproteinorachia [proteins in cerebrospinal fluid $(\mathrm{CSF})>45 \mathrm{mg} / \mathrm{dL}$ ] was found in 23 patients (85.2\%), pleocitosis in CSF in 22 patients $(81.5 \%)$ and eosinorachia occurred in 11 patients (40.7\%). The most significant change in the blood count was eosinophilia, which occurred in nine patients (36\%) (Table III). The time between the beginning of the clinical manifestation and examination ranged from 2-1,095 days (mean = 117.3; $\mathrm{SD}=255.7$ ).

Supplementary data lists the places (city/state) where the infection most likely occurred, the time of follow up and results of specific examinations for schistosomiasis. The serum immune reaction for schistosomiasis was performed on eight patients and seven of these showed positive results (87.5\%). All of these tests were performed using an indirect immunofluorescence reaction with antigens of the digestive tube of adult worms. Positive immune reactions from the CSF were reported for 15 of the 16 evaluated patients $(93.8 \%)$. All of these patients were tested using an enzyme-linked immunosorbent assay and indirect immunofluorescence. Parasitological stool examination was performed on 25 of 27 patients and only 10 patients $(40 \%)$ presented with infected stool. This exam was the least sensitive test specifically used to detect schistosomiasis (Table IV). It is important to note that patients 7,17 and 21 each had three stool samples from different days analysed and no eggs were detected in any of the samples. Patients 4, 11, 18,20 and 26 also had three stool samples from different days analysed and all samples were examined using sedimentation, in addition to the Kato-Katz technique. Similar to patients 7, 17 and 21, no eggs were detected 
TABLE II

Frequency of symptoms autochthonous and allochthonous patients with presumptive diagnosis of schistosomal myeloradiculopathy examined in hospitals of Campinas, São Paulo, Brazil between 1995-2005, before treatment

\begin{tabular}{|c|c|c|c|c|c|c|c|}
\hline & \multicolumn{3}{|c|}{ Autochthonous } & \multicolumn{3}{|c|}{ Imported } & \multirow{2}{*}{$\begin{array}{c}\text { Fisher's exact test } \\
\mathrm{p}\end{array}$} \\
\hline & $\mathrm{N}$ & $\mathrm{n}^{a}$ & $\%$ & $\mathrm{~N}$ & $\mathrm{n}$ & $\%$ & \\
\hline Lower limbs paresis & 14 & 14 & 100 & 11 & 11 & 100 & 1 \\
\hline Bladder dysfunction & 13 & 14 & 93 & 11 & 11 & 100 & 1 \\
\hline Anal dysfunction & 8 & 14 & 57 & 10 & 11 & 91 & 0.09 \\
\hline Erectile dysfunction $^{b}$ & 6 & 8 & 75 & 3 & 3 & 100 & 1 \\
\hline Back pain & 12 & 14 & 86 & 8 & 11 & 73 & 0.623 \\
\hline Pain in lower limbs & 8 & 14 & 57 & 9 & 11 & 82 & 0.233 \\
\hline Other sensitivity changes in lower limbs & 12 & 14 & 86 & 11 & 11 & 100 & 0.486 \\
\hline Walking disability & 9 & 14 & 64 & 7 & 11 & 64 & 1 \\
\hline
\end{tabular}

$a$ : because this is a retrospective study, not all patients provided all information. Only patients whose information was available have been included in the calculation (n); $b$ : to calculate the relative frequency of erectile dysfunction, only men whose clinical records presented this information were included.

\section{TABLE III}

Frequency of unspecific lab findings altered in 27 patients with presumptive diagnosis of schistosomal myeloradiculopathy examined in hospitals of Campinas, São Paulo, Brazil between 1995-2005

\begin{tabular}{lccc}
\hline Lab change & $\mathrm{N}$ & $\mathrm{n}^{a}$ & $\%$ \\
\hline Hyperproteinorachia (protein in CSF $>45 \mathrm{mg} / \mathrm{dL})$ & 23 & 27 & 85.2 \\
Pleocitosis in CSF (white blood cells $>5 / \mathrm{mm}^{3}$ ) & 22 & 27 & 81.5 \\
Eosinorachia & 11 & 27 & 40.7 \\
Eosinophilia $\left(>500 / \mathrm{mm}^{3}\right.$ in the peripheral blood) & 9 & 25 & 36 \\
\hline
\end{tabular}

$a$ : because it is a retrospective study not all patients provided all information. For calculations of relative frequency only patients whose information was available have been included (n); CSF: cerebrospinal fluid.

in any of the samples. Patient 4 has also had a rectal biopsy, which showed no presence of S. mansoni eggs. Importantly, in the patients whose stool samples were submitted to quantitative exams, a low quantity of eggs was detected: two patients had eight eggs per gram of faeces (EPG), one had 19 EPG and one had 48 EPG using the Kato-Katz technique. Only two patients had a spinal cord biopsy done because of a suspected neoplasm (patients 6 and 9); an exudative-necrotic granuloma was found in both of them. Figs 3 and 4 demonstrate the intense granulomatous reaction around the $S$. mansoni egg in the nervous tissue of the spinal cord of patient 6 , who underwent a surgical procedure to investigate the possibility of a spinal cord tumour, which, in the end, was diagnosed as SMR.

All patients were investigated for syphilis, tuberculosis, cysticercosis, AIDS, neoplasia, fungal infections, bacterial infections and vitamin B12 deficiency because they are part of the differential diagnosis for non-traumatic spinal cord lesions. Patient 6 was an exception, as his first diagnosis was of a spinal cord tumour and, with the biopsy, SMR was confirmed. Therefore, the other tests were not required. Diseases such as HTLV infection, autoimmune disease, toxoplasmosis, cytomegalovirus, herpes virus and Chagas disease were also investigated according to the clinical presentation of patients.

The average time between the first visit and the etiological diagnosis was 71 days (mean $=70.6$ days; median $=19 ; \mathrm{SD}=166.9)$. The symptoms presented by the autochthonous and allochthonous patients were equivalent. When compared, the time of manifestation of the first symptoms until complete clinical presentation and the time of manifestation of the first symptoms until the first visit, of autochthonous and allochthonous patients, were also equivalent. Even so, the diagnosis of the autochthonous patients took longer to be defined compared with the allochthonous patients $(\mathrm{p}=0.0247)$ (Table V). The average time for the diagnosis of the autochthonous patients was 88.1 days, which was greater than the time it took to diagnose the allochthonous patients (Table V). The median, maximum and mini- 


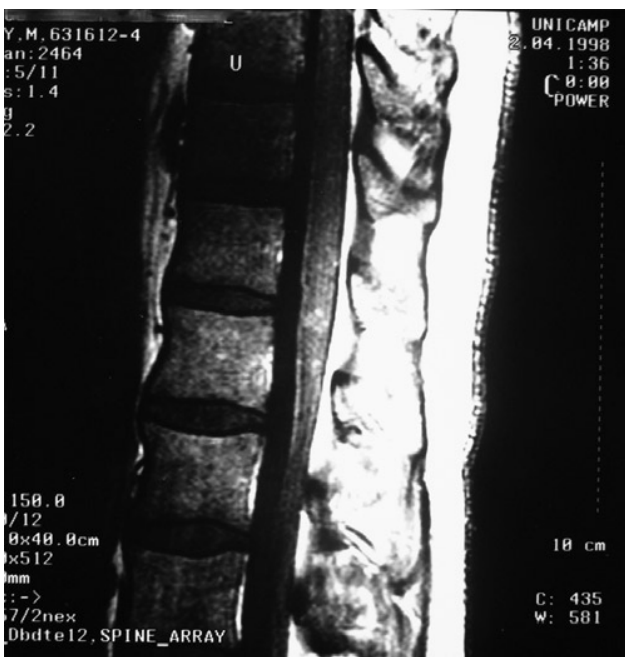

Fig. 1: sagittal magnetic resonance imaging of patient 2 in T2 with granular impregnation pattern of gadolinium magnetic contrast captivation in this image of thoracic-lumbar spine.

\section{TABLE IV}

Frequency of specific exams for schistosomiasis in 27 patients presumptive diagnosis of schistosomal myeloradiculopathy examined with in hospitals of Campinas, São Paulo, Brazil between 1995-2005

\begin{tabular}{lccc}
\hline Lab change & $\mathrm{N}$ & $\mathrm{n}^{a}$ & $\%$ \\
\hline Stool examinations & 10 & 25 & 40 \\
Immune reaction in serum & 7 & 8 & 87.5 \\
Immune reaction in serum & 15 & 16 & 93.8 \\
\hline
\end{tabular}

$a$ : because it is a retrospective study not all patients provided all information. For calculations of relative frequency only patients whose information was available have been included (n).

mum time for diagnosis were also higher for the autochthonous patients. This may be because the physicians may not have suspected the existence of autochthonous SMR in SP.

Twenty-three patients $(85.2 \%)$ were treated with anti-schistosomal drugs and corticosteroids. The remaining four $(14.8 \%)$ were treated with anti-schistosomal drugs only.

Table VI shows the outcome distribution presented by the patients. Only four patients $(14.8 \%)$ demonstrated complete recovery, six patients $(22.2 \%)$ reported a partial recovery with no functional limitations, 13 patients $(48.1 \%)$ had a partial recovery with functional limitations and four $(14.8 \%)$ did not demonstrate a measurable recovery. The worsening of the outcome could be correlated with the delayed introduction of the anti-schistosomal drugs and corticosteroid (Figs 5, 6).

To evaluate the outcome, we compared the clinical status before and after recovery. The interval between

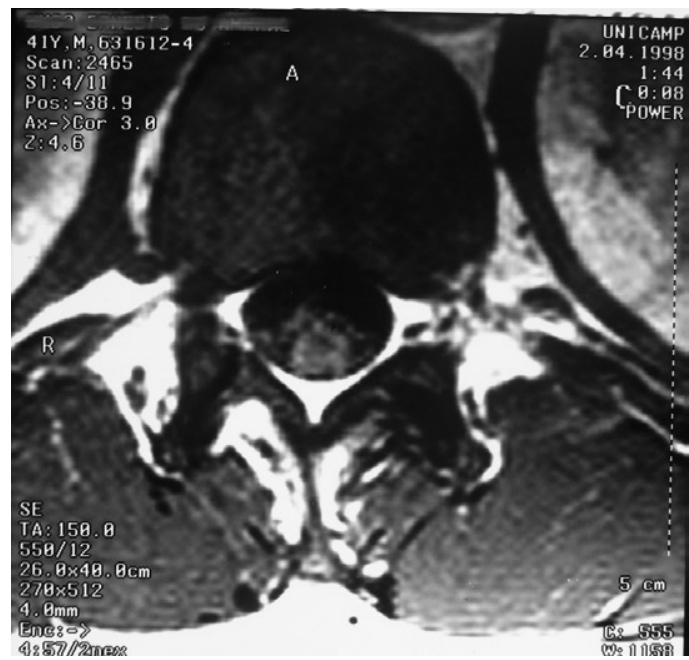

Fig. 2: axial magnetic resonance imaging of patient 2 in T2. It is observed the hypersignal in the medulla on thoracic-lumbar levels.

the beginning of treatment and final evaluation ranged from 10-4,380 days (mean $\pm \mathrm{SD}=1480 \pm 1159.3$; median $=1460$ ). Table VII shows the relative frequency of each of the related symptoms. There was statistically significant recovery for all symptoms, except for erectile dysfunction. In the final evaluation, the most frequent remaining symptoms were walking difficulties $(\mathrm{n}=17 ; 63 \%)$, urinary dysfunction $(\mathrm{n}=13 ; 48.1 \%)$ and erectile dysfunction among males $(\mathrm{n}=11 ; 33.3 \%)$. Table VIII shows the outcome of the autochthonous and allochthonous patients according to the standard classification; the outcome was similar in both groups (autochthonous and allochthonous), but it was not possible to statistically verify the differences between the groups due to the small number of participants. The difference in the frequency of each symptom after the treatment between the two groups was also not statistically significant (Table IX).

Table X shows the outcome of patients in the current study and other reported cases that used the same classifications. While it is not possible to compare the studies precisely because subjective evaluation methodologies were used, the patients examined in Campinas city between 1995-2005 appeared to have a worse outcome than those found in the literature. Because the previous studies are from two research groups from high-endemic areas (MG and Pernambuco), they most likely have more expertise and more resources to diagnose and treat SMR than the professionals in lowendemic areas.

\section{DISCUSSION}

The age and gender distribution of patients presented in this paper were very close to those described in the literature: SMR is a disease that predominantly affects male teenagers and young adults (Ferrari 1999, Silva et al. 2004a). Because it affects a young popu- 

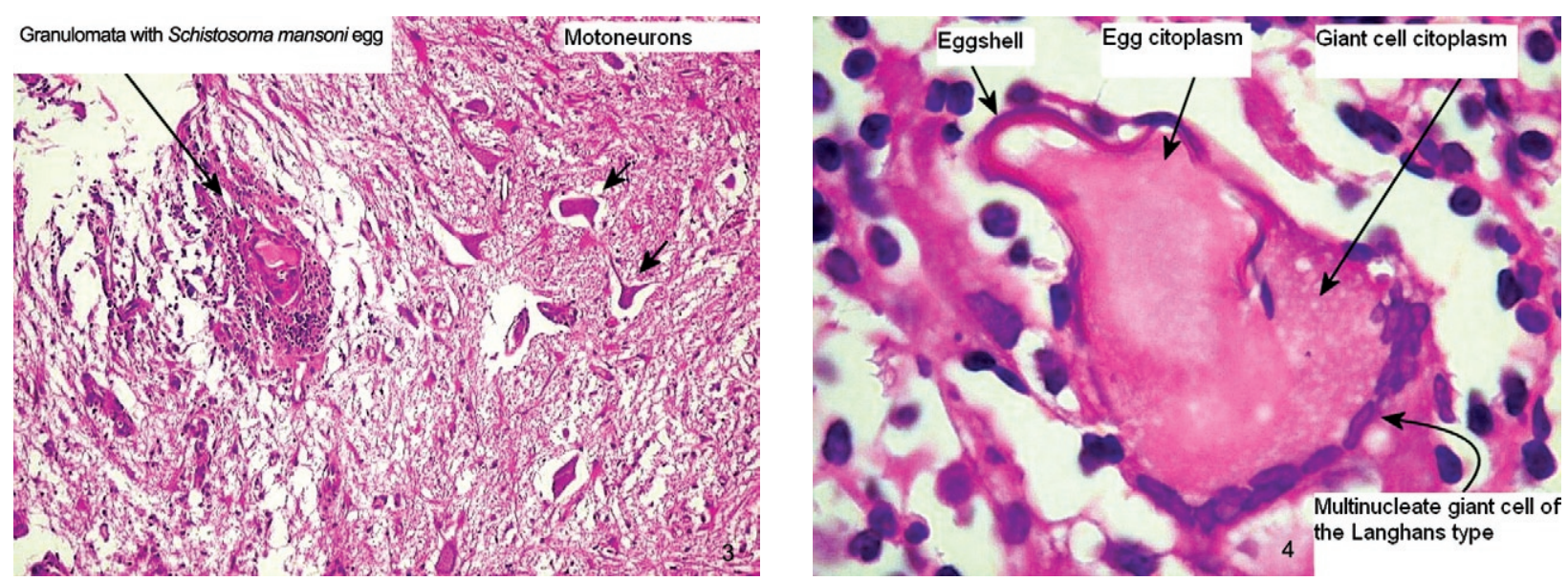

Figs 3, 4: optical microscopy with Hematoxin Eosin coloration where it is verified granuloma in medullar nervous tissue of patient 6 (arrows).

\section{TABLE V}

Time in days passed among clinically relevant moments of autochthonous and imported patients with presumptive diagnosis of schistosomal myeloradiculopathy examined in hospitals of Campinas, São Paulo, Brazil between 1995-2005

\begin{tabular}{|c|c|c|c|c|c|c|c|}
\hline \multirow[b]{2}{*}{ Interval in days between } & \multicolumn{3}{|c|}{ Autochthonous } & \multicolumn{3}{|c|}{ Allochthonous } & \multirow{2}{*}{$\begin{array}{c}\text { Mann- } \\
\text { Whitney's test } \\
\mathrm{p}\end{array}$} \\
\hline & Mean & Median & $\mathrm{SD}$ & Mean & Median & SD & \\
\hline First symptoms and complete clinical condition & 42.6 & 9 & 88.3 & 174.6 & 9 & 291.3 & 0.804 \\
\hline First symptoms and the first visit & 47.2 & 10 & 107.3 & 213.7 & 22 & 369.5 & 0.336 \\
\hline First visit and diagnosis & 112 & 26 & 224.3 & 23.9 & 9 & 42.7 & 0.0247 \\
\hline Time of follow-up & 1833.5 & 2036 & 1019.4 & 1077.9 & 485.5 & 1231.7 & 0.381 \\
\hline
\end{tabular}

SD: standard deviation.

lation at the beginning of their economically active life and as recovery is often associated with lingering symptoms with serious consequences for life quality of the individual and his family, the morbidity associated with this disease should be reinforced.

As expected, the clinical presentation of SMR in the autochthonous group was not different from the presentation of the non-autochthonous group and it was not different from that described in the literature (Ferrari 1999, 2004, Peregrino et al. 2002, Transverse Myelitis Consortium Working Group 2002, Silva et al. 2004a, b): a spinal cord disease of acute or sub-acute character with sensitive, motor and autonomic symptomatology. Importantly, regardless of the level of endemicity, patient exposure to contaminated bodies of water in transmission areas should suggest this etiology to healthcare professionals. The majority of patients $(51.9 \%, 14$ patients) were classified as autochthonous in a region where the least patients notified in the SINAN are autochthonous $(23.9 \%)$. This data suggests that the proportion of patients with spinal cord forms among the total of schistosomiasis-carriers is higher among patients from low-endemic areas than among patients from high-endemic areas.
The lab findings were not different from those described in the literature: blood eosinophilia and pleocitosis, hyperproteinorachia and the presence of eosinophils in the CSF. As far as the schistosomiasisspecific examinations were concerned, the sensitivity of stool examinations was low; only 10 patients (40\%) were positive among of those tested. This made this screening method the least sensitive exam among other schistosomiasis-specific exams. Patient 4 had no eggs in his stool and rectal biopsy, which delayed his diagnosis. Exposure to $S$. mansoni can only be confirmed using blood tests some months after infection and the delay in diagnosis likely contributed to the development of symptoms that remained after resolution. Carod-Artal and Vargas (2004) describe a case of one patient with SMR who had eggs in his stool and a negative rectal biopsy. In this case, the diagnosis was made based on a positive immune reaction in the CSF. Camargos et al. (2005) describe another case where three serial samples were negative and the CSF and serum immune reaction were positive, allowing for the diagnosis. The sensitivity of stool examination in previously reported cases varies greatly. Ferrari et al. (2004) has found a sensitivity of $59.2 \%$ among 54 patients evaluated us- 


\section{TABLE VI}

Distribution of 27 patients with assumed diagnosis of schistosomal myeloradiculopathy attended in hospitals of Campinas, São Paulo, Brazil between 1995-2005, according to evolution

\begin{tabular}{lcc}
\hline & \multicolumn{2}{c}{ Frequency } \\
\cline { 2 - 3 } Outcome & $\mathrm{N}\left(\mathrm{n}^{a}=27\right)$ & $\%$ \\
\hline $\begin{array}{l}\text { Complete recovery } \\
\text { Partial recovery with } \\
\text { no functional limitations }\end{array}$ & 4 & 14.8 \\
$\begin{array}{l}\text { Partial recovery } \\
\text { with functional limitations }\end{array}$ & 13 & 22.2 \\
Absence of recovery & 4 & 48.1 \\
\hline
\end{tabular}

$a$ : because it is a retrospective study not all patients provided all information. For calculations of relative frequency only patients whose information was available have been included (n). ing 3-5 stool samples. In the series of 13 patients studied by Carod-Artal et al. (2004) the sensitivity of stool examination was $15.4 \%$; in the thesis by Lima (2004), in which 65 patients were studied, the sensitivity was $44.6 \%$. Silva et al. (2004b) reported a sensitivity of $25 \%$ in a series of 16 patients who all had three stool samples analysed, while Peregrino et al. (2002) found a sensitivity of $42.5 \%$ in a series of 80 patients. Finally, Peregrino et al. (2002) reported a sensitivity of $42.9 \%$ and Andrade (1986) reported a sensitivity of $25 \%$.

The previously reported sensitivity of the CSF immune reaction was higher $(92.8 \%)$ than the sensitivity observed in the current study $(87.5 \%)$. Because this is a retrospective study, it is possible to rule out other selection biases and other factors, such as methodological differences. However, we can affirm that, in general, the immune reactions in the CSF or serum were more sensitive than stool examination. As the parasitological tests are always used as pattern exams for the programs of schistosomiasis control, the ability to identify patients that are vulnerable to this form of schistosomiasis is very low.

TABLE VII

Frequency of symptoms observed before and after recovery in 27 patients with presumptive diagnosis of schistosomal myeloradiculopathy examined in hospitals of Campinas, São Paulo, Brazil between 1995-2005

\begin{tabular}{lccccccc}
\hline & \multicolumn{3}{c}{ Pre-treatment } & & Post-treatment & Fisher's exact test \\
\hline & $\mathrm{N}$ & $\mathrm{n}^{a}$ & $\%$ & $\mathrm{~N}$ & $\mathrm{n}^{a}$ & $\%$ & $\mathrm{p}$ \\
Walking disability & 16 & 27 & 59.3 & 4 & 27 & 14.8 & 0.002 \\
Lower limbs paresis & 27 & 27 & 100 & 17 & 27 & 63 & 0.001 \\
Bladder dysfunction & 25 & 27 & 92.6 & 13 & 27 & 48.1 & 0.001 \\
Anal dysfunction $^{\text {Erectile dysfunction }}{ }^{b}$ & 19 & 27 & 70.4 & 6 & 27 & 22.2 & $<0.001$ \\
N & 9 & 12 & 75 & 5 & 15 & 33.3 & $0.054^{c}$ \\
\hline
\end{tabular}

$a$ : because it is a retrospective study not all patients provided all information. For calculations of relative frequency only patients whose information was available have been included (n); $b$ : for calculation of relative frequency of erectile dysfunction women have been excluded from the calculation; $c$ : the sole variable, which proportion has not shown statistically significant difference before and after recovery was erectile dysfunction.

\section{TABLE VIII}

Distribution of outcome of autochthonous and allochthonous patients with presumptive diagnosis of schistosomal myeloradiculopathy examined in hospitals of Campinas, São Paulo, Brazil between 1995-2005

\begin{tabular}{|c|c|c|c|c|}
\hline \multirow[b]{2}{*}{ Outcome } & \multicolumn{4}{|c|}{ Frequency } \\
\hline & Autochthonous & $\%$ & Allochthonous & $\%$ \\
\hline 1. Complete recovery & 3 & 21.4 & 1 & 9.1 \\
\hline 2. Partial recovery with no functional limitations & 1 & 7.1 & 3 & 27.3 \\
\hline 3. Partial recovery with functional limitations & 7 & 50 & 6 & 54.5 \\
\hline 4. Absence of recovery & 3 & 21.4 & 1 & 9.1 \\
\hline Favorable $1+2$ & 4 & - & 4 & - \\
\hline Unfavorable $3+4$ & 10 & - & 7 & - \\
\hline Total & 14 & - & 11 & - \\
\hline
\end{tabular}


TABLE IX

Frequency of symptoms in autochthonous and allochthonous patients with presumptive diagnosis of schistosomal myeloradiculopathy examined in hospitals of Campinas, São Paulo, Brazil between 1995-2005, after treatment

\begin{tabular}{|c|c|c|c|c|c|c|c|}
\hline & \multicolumn{3}{|c|}{ Autochthonous } & \multicolumn{3}{|c|}{ Allochthonous } & \multirow{2}{*}{$\begin{array}{c}\text { Fischer's exact test } \\
\mathrm{p}\end{array}$} \\
\hline & $\mathrm{N}$ & $\mathrm{n}^{a}$ & $\%$ & $\mathrm{~N}$ & $\mathrm{n}^{a}$ & $\%$ & \\
\hline Lower limbs paresis & 8 & 14 & 57 & 9 & 11 & 82 & 0.233 \\
\hline Bladder dysfunction & 7 & 14 & 50 & 5 & 10 & 50 & 1 \\
\hline Anal dysfunction & 3 & 14 & 21 & 2 & 10 & 20 & 1 \\
\hline Erectile dysfunction $^{a}$ & 4 & 10 & 40 & 1 & 5 & 20 & 0.600 \\
\hline Thoracic or back pain & 12 & 14 & 86 & 8 & 11 & 73 & 0.623 \\
\hline Pain in lower limbs & 8 & 14 & 57 & 9 & 11 & 82 & 0.233 \\
\hline Other sensitivity changes in lower limbs & 12 & 14 & 86 & 11 & 11 & 100 & 0.486 \\
\hline Walking disability & 3 & 14 & 21 & 1 & 11 & 9 & 0.604 \\
\hline
\end{tabular}

$a$ : to calculate the relative frequency of erectile dysfunction, only men whose clinical records presented this information were included.

TABLE X

Comparison between data collected in literature and the evolution of 27 patients with presumptive diagnosis of schistosomal myeloradiculopathy examined in hospitals of Campinas, São Paulo, Brazil between 1995-2005

\begin{tabular}{|c|c|c|c|c|c|c|}
\hline & \multicolumn{2}{|c|}{ Current study } & \multicolumn{2}{|c|}{ Ferrari (2004) } & \multicolumn{2}{|c|}{ Peregrino et al. (2002) } \\
\hline & $\begin{array}{c}\mathrm{N} \\
\left(\mathrm{n}^{a}=27\right)\end{array}$ & $\%$ & $\begin{array}{c}N \\
(n=63)\end{array}$ & $\%$ & $\begin{array}{c}\mathrm{N} \\
(\mathrm{n}=80)\end{array}$ & $\%$ \\
\hline 1. Complete recovery & 4 & 14.8 & 20 & 31.7 & 31 & 38.8 \\
\hline 2. Partial recovery with no functional limitations & 6 & 22.2 & 18 & 28.6 & 33 & 41.3 \\
\hline 3. Partial recovery with functional limitations & 13 & 48.1 & 16 & 25.4 & 9 & 11.3 \\
\hline 4. Absence of recovery & 4 & 14.8 & 9 & 14.3 & 7 & 8.8 \\
\hline Favorable $1+2$ & 10 & 37 & 38 & 60.3 & 64 & 80 \\
\hline Unfavorable $3+4$ & 17 & 63 & 25 & 39.7 & 16 & 20 \\
\hline
\end{tabular}

$a$ : because it is a retrospective study not all patients provided all information. For calculations of relative frequency only patients whose information was available have been included (n).

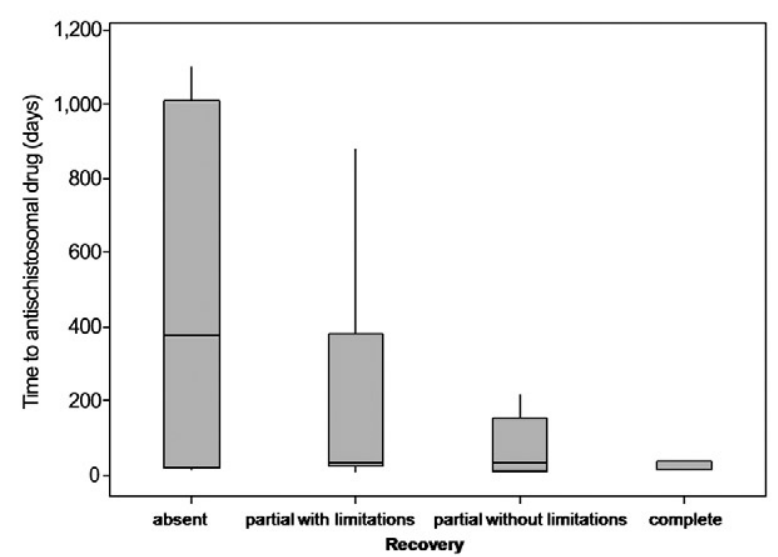

Fig. 5: time in days since the beginning of clinical symptoms until the introduction of anti-schistosomal drug according to the outcome.

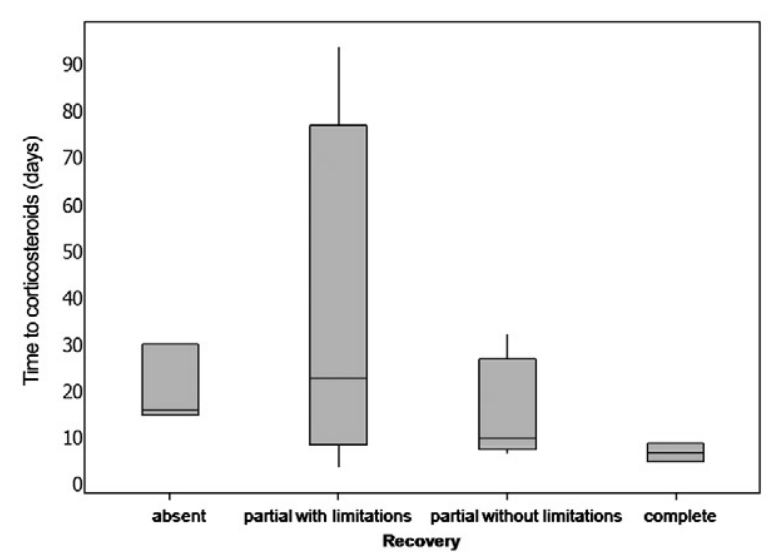

Fig. 6: time in days since the beginning of clinical symptoms until the introduction of corticosteroid according to the outcome. 
Considering the fact that most SMR patients have intestinal forms of schistosomiasis, the low sensitivity of the stool exams is not surprising and it makes diagnosis more difficult. In spite of this fact, however, the low sensitivity does not hinder the treatment. A physician examining a patient suspected of SMR must investigate the etiology with more sensitive exams such as a mucous rectal biopsy or immunological methods. A problem, however, is that immune exams are not always easily or promptly available, particularly in low-endemic areas. The difficulty in performing the immunological methods, as well as the limited knowledge of the disease, may have contributed to the delay in the diagnosis of the autochthonous and allochthonous patients in this study. The time between the first visit and the diagnosis was 70.6 days (median $=19$; $\mathrm{SD}=166.9$ ). This delay may have contributed to the poor outcome of the 17 patients $(62.9 \%)$ that had some significant impairment in their daily lives (Table VI). The relationship between the delay in the initiation of treatment and unfavourable outcome is shown in Figs 5 and 6.

Another relevant aspect is that the time necessary to diagnose the autochthonous patients was longer than the time to diagnose the allochthonous patients $(p=0.0247)$ (Table V). One possible explanation for this difference is the fact that Campinas is a region of low endemicity. Therefore, not all physicians would consider schistosomiasis for a patient who is originally from this area. Additionally, the difficulty in diagnosing this disease stems from errors and misdiagnoses. Therefore, the identified cases could be just a few out of many cases that occurred during this time. In order to decrease the delay in diagnosis and sub-diagnosis, it is necessary to warn neurologists, urologists, physicians who work in emergency rooms and other health care professionals about the occurrence of this disease within this region.

The epidemiological vigilance system (SINAN) has not paid the necessary attention to the identification of SMR cases, with only $41 \%$ of the patients notified. Moreover, there is no space in the epidemiological file to register SMR. Therefore, the 11 notified patients have not had the neurological form of schistosomiasis registered at SINAN.

Even though the outcome verified post-treatment was significant, it was not enough to be satisfactory because only four patients (14.8\%) had a complete recovery and the remaining symptoms have deeply lowered the quality of life of the remaining patients. The most observed remaining symptoms were lower limb weakness $(\mathrm{n}=17 ; 63 \%)$, urinary dysfunction $(\mathrm{n}=13 ; 48.1 \%)$ and erectile dysfunction $(\mathrm{n}=5 ; 33.3 \%)$. Silva et al. (2004a) reported weakness in nine patients $(56.3 \%)$ in a study that examined 16 patients with another evaluation six months after the treatment. Sexual dysfunction in $40 \%$ of male patients (4 out of 10) was also observed and urinary dysfunction was observed in $37.5 \%$ of the patients (Silva et al. 2004b). The lingering urological symptoms do not seem to respond well to clinical treatment, as observed in this paper and other reports from the literature (Lima 2004, Silva et al. 2004b). This is reflected both in symptom maintenance and in changes in the exams to evaluate urinary function. Lima (2004) has evaluated the occurrence of urological symptoms in patients after recovery in a prospective study of 65 patients. Even among these patients, who received the current acceptable treatment (anti-schistosomal drugs and corticosteroids), the occurrence and changed exams of urinary function were not significantly different before or after treatment, with re-evaluation after nine months. The urological lingering symptoms include both urinary function and erectile function, but the latter aspect was neglected even in studies performed by urologists (Gomes et al. 2002, 2005, Lima 2004) and this opinion is shared by other researchers (Ferrari 1999, Silva et al. 2004b).

SMR and control policies - Many previous studies have demonstrated the occurrence of SMR in patients from non-endemic areas. Most of these reports detail patients from European or North American countries that have acquired SMR after being infected during travel in endemic countries (CDC 1984, Gellido et al. 2000, Chen et al. 2006). The current paper describes cases of patients from a low-endemic area. Hepatosplenic schistosomiasis is a disease more commonly diagnosed in patients living in high-endemic areas with repeated re-infections and, while SMR can occur in any schistosomiasis carrier, it seems to be more common in those that have a mild intestinal form. Several researchers have warned of the importance of distinguishing SMR from hepatosplenic schistosomiasis regarding the treatment strategy. In the latter, a mass treatment based on a decrease of worm burden in the carriers is enough to control the disease. SMR, on the other hand, will occur whenever intestinal schistosomiasis occurs, that is, as long as the transmission of schistosomiasis continues (WHO 1998, Lambertucci et al. 2000, Richter 2003).

We have gained a greater understanding of the clinical and pathological characteristics of SMR in the last decades, but little is known about its incidence. In the past few years, the Brazilian Ministry of Health has begun to pay more attention to this disease and this change can be seen in publications from the Ministry. In the Guide of Epidemiological Surveillance, 5th edition, published in 2002, the sole sentence regarding SMR was "Another important form to be considered is the neuroschistosomiasis" (MS/SVS 2002). However, in the 6th edition of the Guide of Epidemiological Surveillance, published in 2005, more emphasis has been placed on the disease: "Among other ectopic forms, the most serious is neuroschistosomiasis (schistosomal myeloradiculitis) whose prevalence in endemic areas has been underestimated. The diagnosis is difficult, but the clinical and epidemiological suspicion leads, safely, to the presumptive diagnosis. Its early diagnosis and therapy prevent the progression of the disease to non-competent clinical status and deaths." (MS/SVS 2005). In 2006 preliminary data detailing hepatosplenic schistosomiasis and neurological morbidity in MG from members of the Secretary of Health of Minas Gerais, Ministry of Health and Universidade Federal de Minas Gerais were published (Drummond et al. 2006). While this paper describes the occurrence of SMR in patients residing in metropolitan 
areas and other regions of $\mathrm{MG}$, it was not designed to investigate either the likely loci of infection or the standard pattern of exposure. In 2006, the Ministry of Health released a guide exclusively on this topic: Guide of Epidemiological Surveillance and Control of Schistosomal Myeloradiculopathy (MS/SVS 2006). Therefore, there seems to be an increase in acknowledging the importance of this form of schistosomiasis in the current spectrum of epidemiology.

The current paper shows the occurrence of SMR in patients in an urban area of low endemicity who had been infected during recreational activities. As the importance of SMR is recognised in low endemicity (or low prevalence) settings, a few choices have to be made. The findings of this study reinforce this idea and point to a need for changing the paradigms and concepts used for controlling schistosomiasis, so that the control of the medullary form of the disease can be effective. To eliminate SMR, it is necessary to eliminate schistosomiasis transmission and not to simply decrease the worm load in patients.

There are many factors that may have contributed to the increase in the identification of SMR cases, including diagnostic resource improvements, increased ecotourism activities with the exposure of new populations, the maintenance of schistosomiasis global prevalence and an increased area of transmission, including urban areas (Silva 1985, Enk et al. 2003, Agbessi et al. 2006). The instruments for surveillance and control currently used in the programs for schistosomiasis have not been sufficient to decrease the SMR problem or to control it. More studies are needed to improve our knowledge of the epidemiology of the neurological forms of schistosomiasis. Modification in the monitoring and control programs of schistosomiasis is needed for decrease schistosomal morbidity. It is very advisable to introduce more sensitive methods within the public health services to diagnose chronic intestinal schistosomiasis as a means to avoid SMR, particularly in areas of low prevalence. Technology to introduce serology as routine diagnostic tool in basic health services is already available (Dias et al. 1992, Silva et al. 1998, Oliveira et al. 2005). More studies are needed to develop more effective drugs to cure schistosomiasis and more sensitive methods to verify the treatment effectivity. It will be useful to disclose SMR and further educate professionals about examining these patients both in the studied region and in other areas of low and high prevalence. A secondary advantage of disclosing the existence of severe forms of schistosomiasis is the increase in the control measures taken by the population to eliminate the infection.

There is a need for a detailed study of SMR focusing on the epidemiological aspects such as prevalence, incidence and proportion of SMR cases among schistosomiasis-carriers in areas of high and low endemicity and predisposing factors.

\section{ACKNOWLEDGEMENTS}

To Dr Luciano de Souza Queiroz (Queiroz \& Zanardi 2006), from the Departamento de Anatomia Patológica, FCM-UNICAMP, for providing optical microscopy pictures of patient 6 .

\section{REFERENCES}

Agbessi CA, Bourvis N, Fromentin M, Jaspard M, Teboul F, Bougnoux ME, Hanslik T 2006. Acute schistosomiasis in French travellers. Rev Med Interne 27: 595-599.

Andrade AN 1986. Neuroesquistossomose. Arq Neuropsiquiatr 44: 175-179.

Camargo-Neves VLF. Esquistossomose mansônica. Superintendência de Controle de Endemias - SUCEN 2007. [cited in 2007 jan 20]. Available from: http://www.saude.sp.gov.br.

Camargos ST, Dantas FR, Teixeira AL 2005. Schistosomal myelopathy mimicking spinal cord neoplasm. Scand J Infect Dis 37: 365-367.

Carod-Artal FJ, Vargas AP 2004. Myelopathy due to Schistosoma mansoni. A description of two cases and review of the literature. Rev Neurol 39: 137-141.

Carod-Artal FJ, Vargas AP, Horan TA, Marinho PB, Coelho Costa PH 2004. Schistosoma mansoni myelopathy: clinical and pathologic findings. Neurology 63: 388-391.

CDC - Centers of Disease Control 1984. Acute schistosomiasis with transverse myelitis in American students returning from Kenya. MMWR Morb Mortal Wkly Rep 33: 445-447.

Chen AW, Alam MH, Williamson JM, Brawn LA 2006. An unusually late presentation of neuroschistosomiasis. J Infect 53: 155-158.

Dias LC, Marçal Júnior O, Glasser CM, Kanamura HY, Hotta LK 1992. Control of schistosomiasis mansoni in a low transmission area. Mem Inst Oswaldo Cruz 87 (Suppl. IV): 233-239.

Drummond SC, Silva LC, Amaral RS, Sousa-Pereira SR, Antunes CM, Lambertucci JR 2006. Morbidity of schistosomiasis mansoni in the state of Minas Gerais, Brazil. Mem Inst Oswaldo Cruz 101 (Suppl. I): 37-44.

Enk MJ, Amorim A, Schall VT 2003. Acute schistosomiasis outbreak in the metropolitan area of Belo Horizonte, Minas Gerais: alert about the risk of unnoticed transmission increased by growing rural tourism. Mem Inst Oswaldo Cruz 98: 745-750.

Faria AV, Cerqueira EMF, Reis F, Pirani C, Damasceno BP, Menezes Neto JR, Zanardi VA 2002. Apresentações da esquistossomose no sistema nervoso central: correlação clinica e radiológica. $R a$ diol Bras 35: 47-50.

Ferrari TC 1999. Spinal cord schistosomiasis. A report of 2 cases and review emphasizing clinical aspects. Medicine (Baltimore) 78: 176-190.

Ferrari TC 2004. Involvement of central nervous system in the schistosomiasis. Mem Inst Oswaldo Cruz 99 (Suppl. I): 59-62.

Ferrari TC, Moreira PR, Cunha AS 2001. Spinal-cord involvement in the hepato-splenic form of Schistosoma mansoni infection. Ann Trop Med Parasitol 95: 633-635.

Ferrari TC, Moreira PR, Cunha AS 2004. Spinal cord schistosomiasis: a prospective study of 63 cases emphasizing clinical and therapeutic aspects. J Clin Neurosci 11: 246-253.

Gellido CL, Onesti S, Llena J, Suarez M 2000. Spinal schistosomiasis. Neurology 54: 527.

Gomes CM, Hisano M, Machado LR, Figueiredo JA, Lucon AM, Trigo-Rocha FE 2005. Urological manifestations of chronic schistosomal myeloradiculopathy. BJU Int 96: 853-856.

Gomes CM, Trigo-Rocha F, Arap MA, Gabriel AJ, Alaor de Figueiredo J, Arap S 2002. Schistosomal myelopathy: urologic manifestations and urodynamic findings. Urology 59: 195-200.

Gonçalves EC, Fonseca AP, Pittella JE 1995. Frequency of schistosomiasis mansoni, of its clinicopathological forms and of the ectopic locations of the parasite in autopsies in Belo Horizonte, Brazil. J Trop Med Hyg 98: 289-295. 
Lambertucci JR 1993. Schistosoma mansoni: pathological and clinical aspects. In Jordan P, Webbe G, Sturrock RF (eds.), Human Schistosomiasis, Cab International, Wallingford, p. 195-235.

Lambertucci JR, Serufo JC, Gerspacher-Lara R, Rayes AA, Teixeira R, Nobre V, Antunes CM 2000. Schistosoma mansoni: assessment of morbidity before and after control. Acta Trop 77: 101-109.

Lambertucci JR, Sousa-Pereira SR, Silva LC 2005. Myeloradiculopathy in acute schistosomiasis mansoni. Rev Soc Bras Med Trop 38: 277-278.

Lima PR 2004. Análise das alterações vésico-esfincterianas em pacientes com mielopatia esquistossomótica mansônica antes $e$ após o tratamento medicamentoso da doença, $\mathrm{PhD}$ Thesis, Universidade Federal de São Paulo, São Paulo, 99 pp.

Lima WL, Tose CS, Ferreira RE 1999. Diagnóstico de neuroesquistossomose medular após anestesia subaracnóidea: relato de caso. Rev Bras Anestesiol 49: 338-340.

MS/CNS - Ministério da Saúde Brasil/Conselho Nacional de Saúde 1996. Resolução 196 de 10 de outubro de 1996. [cited 2006 Dec 20]. Available from: http://conselho.saude.gov.br/resolucoes/reso_96.htm.

MS/SVS - Ministério da Saúde Brasil/Secretaria de Vigilância em Saúde 2002. Guia de vigilância epidemiológica, 5th ed., MS, Brasília, 842 pp.

MS/SVS - Ministério da Saúde Brasil/Secretaria de Vigilância em Saúde 2005. Guia de vigilância epidemiológica, 6th ed., MS, Brasília, 816 pp.

MS/SVS - Ministério da Saúde Brasil/Secretaria de Vigilância em Saúde 2006. Guia de vigilância epidemiológica e controle da mielorradiculopatia esquistossomótica, MS, Brasília, 32 pp.

Nobre V, Silva LC, Ribas JG, Rayes A, Serufo JC, Lana-Peixoto MA, Marinho RF, Lambertucci JR 2001. Schistosomal myeloradiculopathy due to Schistosoma mansoni: report on 23 cases. Mem Inst Oswaldo Cruz 96 (Suppl.): 137-141.

Oliveira EJ, Kanamura HY, Lima DM 2005. Efficacy of an enzymelinked immunosorbent assay as a diagnostic tool for schistosomiasis mansoni in individuals with low worm burden. Mem Inst Oswaldo Cruz 100: 421-425.

Peregrino AJ, Puglia PM, Nóbrega JP, Livramento JA, Marques-Dias MJ, Scaff M 2002. Esquistossomose medular: análise de 80 casos. Arq Neuropsiquiatr 60: 603-608.

Pittella JE 1991. The relation between involvement of the central nervous system in schistosomiasis mansoni and the clinical forms of the parasitosis. A review. J Trop Med Hyg 94: 15-21.

Pittella JE 1997. Neuroschistosomiasis. Brain Pathol 7: 649-662.

Queiroz LS, Zanardi VA 2006. Curso de Neuroimagem para graduação em Medicina. Departamento de Anatomia Patológica FCM - Unicamp. [cited in 2006 dec 20]. Available from: http:// anatpat.unicamp.br/casos.html.
Richter J 2003. The impact of chemotherapy on morbidity due to schistosomiasis. Acta Trop 86: 161-183.

SEP/SP - Secretaria de Economia e Planejamento do Estado de São Paulo. Agência Metropolitana de Campinas. 2007. [cited in 2007 jan. 20]. Available from: http://www.planejamento. sp.gov.br.

SES/CVE-SP - Secretaria de Estado da Saúde/Centro de Vigilância Epidemiológica. São Paulo. Esquistossomose 2008. [cited 2008 dec 01]. Available from: http://cve.saude.sp.gov.br.

Silva LC, Maciel PE, Ribas JG, Pereira SR, Serufo JC, Andrade LM, Antunes CM, Lambertucci JR 2004a. Mielorradiculopatia esquistossomótica. Rev Soc Bras Med Trop 37: 261-272.

Silva LC, Maciel PE, Ribas JG, Souza-Pereira SR, Antunes CM, Lambertucci JR 2004b. Treatment of schistosomal myeloradiculopathy with praziquantel and corticosteroids and evaluation by magnetic resonance imaging: a longitudinal study. Clin Infect Dis 39: 1618-1624.

Silva LJ 1985. Crescimento urbano e doença: a esquistossomose no município de São Paulo (Brazil). Rev Saude Publica 19: 1-7.

Silva LJ 1992. A esquistossomose mansônica no Estado de São Paulo: origens, distribuição, epidemiologia e controle, Associate professorship Thesis, UNICAMP, Campinas, 140 pp.

Silva RM, Kanamura HY, Camargo ED, Chiodelli SG, Nakamura PM, Gargioni C, Vellosa SA, Antunes JL 1998. A comparative study on IgG-ELISA, IgM-IFT and Kato-Katz methods for epidemiological purposes in a low endemic area for schistosomiasis. Mem Inst Oswaldo Cruz 93 (Suppl. I): 279-282.

SMS - Secretaria Municipal de Saúde de Campinas. TabNet Campinas. 2007. [cited in 2007 jan. 20]. Available from: http://tabnet.saude. campinas.sp.gov.br.

Tedrus GM, Fonseca LC, Nogueira-Júnior E 1999. Esquistossomose do sistema nervoso central. Rev Cienc Med Campinas 8: 28-30.

Tedrus GM, Viana MA, Fonseca LC, Araújo CA 1996. Neuroesquistossomose. Rev Cienc Med Campinas 5: 21-23.

Transverse Myelitis Consortium Working Group 2002. Proposed diagnostic criteria and nosology of acute transverse myelitis. $\mathrm{Neu}$ rology 59: 499-505.

WHO - World Health Organization 1998. Report of the WHO informal consultation on schistosomiasis control. Geneva 2-4 December. $\mathrm{WHO} / \mathrm{CDS} / \mathrm{CPC} / \mathrm{SIP} / 99.2$.

WHO - World Health Organization 2001. Report of informal consultation on schistosomiasis in low transmission areas: control strategies and criteria for elimination, WHO, Geneva, 52 pp.

WHO - World Health Organization 2002. Prevention and control of schistosomiasis and the soil-transmitted helminthiasis, Report of a WHO Expert Committee, Geneva, 73 pp. 